\title{
Theofilos
}

A Nordic open access journal in Theology, Philosophy and Culture

Published by NLA University College - in partnership with Johannelund School of Theology

Available at www.theofilos.no

2018. The theme is "Science, Natural Theology, and Christian Apologetics". It has been edited by our Chief Editor, our Book Editor Bjørn Hinderaker, and with Peter S. Williams as our Guest Editor. We are truly grateful for Pete's assistance in editing all the texts and for his own substantial contributions, and we also extend our thanks to all the other contributors. So, without further ado, I will let our Guest Editor introduce the exciting content of this first open access issue of Theofilos.

Tolle et lege!

Stefan Lindholm, Editor

Uppsala, Sweden, December 2020

\section{Introducing the Theofilos Supplement issue on Science, Natural Theology, and Christian Apologetics}

In early 2018, I proposed an annual research 'symposium' to be held at the NLA Gimlekollen Campus (with academic presentations and discussion, but with coffee replacing the traditional Greek wine). I was delighted to see NLA colleagues run with the concept, such that the Veritas Research Symposium launched in October 2018 now is an annual event at the campus in Kristiansand, Norway. The symposium's focus is research on challenges, themes, and issues in Christian apologetics and related missiological, theological and philosophical areas. The symposium is closely linked to the annual Norwegian Veritas Conference. ${ }^{1}$

The theme chosen for the inaugural symposium was Science, Natural Theology, and Christian Apologetics. This is an exciting topic for interdisciplinary research of key relevance to contemporary culture. Once we had a view of the proposed papers, it became clear that they fell naturally into three sub-topics which we used to structure the Symposium: 'Issues in Genesis', 'Issues in Natural Theology' and 'Issues in Contemporary Popular Culture'.

Papers presented at the 2018 symposium were subsequently read and commented upon by the co-editors of this Supplement issue of Theofilos (Chief Editor Lars Dahle, Book Editor Bjørn Hinderaker and myself as Guest Editor), before being revised by the contributors and submitted to the standard double blind peer review process.

\section{The academia section}

The editorial and the peer review procedures resulted in seven academic articles from the Symposium. The articles cover the three topical areas mentioned above and represent a fascinating spectrum of positions and perspectives.

\section{Issues in Genesis}

- Jens Bruun Kofoed (Fjellhaug International University College):

'Approaching Genesis and science: Hermeneutical principles and a case study'

- Gunnar Innerdal (NLA University College, Bergen): 'The origin of sin - in dialogue with natural science'

\section{Issues in Natural Theology}

- Knut-Willy Scether (Volda University College): 'The apologetic fruitfulness of a revised natural theology'

- Atle Søvik (MF Norwegian School of Theology, Religion and Society, Oslo): 'How to formulate the fine-tuning argument for the existence of God?'

- Steinar Thorvaldsen (UiT, The Arctic University of Norway, Tromsø): 'Intelligent design and natural theology' 


\section{Issues in Contemporary Popular Culture}

- Peter S. Williams (NLA University College, Kristiansand): 'Scientific Rebuttals to "Ancient Aliens" as Popular Alternatives to Biblical History'

- Margunn Serigstad Dable (NLA University College, Kristiansand) and Ingvild Thu Kro (NLA University College, Kristiansand): “Unraveling the Mystery": Assessing The Big Bang Theory as a Secular Fictional Universe'

\section{The other sections}

This special Supplement issue also presents a selection of thematically relevant contributions in the usual forum, biblos and nota bene sections of Theofilos.

We are especially pleased to have received permission to include previously published articles by Oxford emeritus professor John Lennox and Genesis specialist C. John Collins. As keynote speaker at the Veritas Conference in 2018, Lennox visited our Symposium with an inspirational greeting. The essay from Collins highlights some significant, and maybe unexpected, contributions from Francis Schaeffer and C.S. Lewis, influential Christian apologists in the 20th century.

\section{forum}

- Peter S. Williams (NLA University College, Kristiansand), 'Natural Theology and Science in Contemporary Apologetic Context: An Overview'

- John Lennox (University of Oxford), 'Science and Faith: Friendly Allies, Not Hostile Enemies' (Reprinted with permission)

- C. John ('Jack') Collins (Covenant Theological Seminary, St. Louis), 'Freedoms and Limitations: C. S. Lewis and Francis Schaeffer as a Tag Team' (Reprinted from Firstfruits of a New
Creation: Essays in Honor of Jerram Barrs with permission)

- Bjørn Hinderaker (NLA University College, Kristiansand) and Lars Dahle (NLA University College, Kristiansand), 'Genesis 1-3 as a Worldview Story: Exploring the Story and Its Worldview with Francis A. Schaeffer, C. S. Lewis, and C. John Collins'

\section{biblos}

- 'Four Dozen Key Resources on Apologetics and Natural Theology in an Age of Science', as curated and annotated by Peter S. Williams (NLA University College, Kristiansand).

\section{nota bene}

- Iain Morris (Kharis Productions), 'How convincing is the case for God? The "Finnes Gud?" television series offers you the chance to assess it!'

- Finnes Gud? and The God Question for Starters

\section{A final note}

The editorial team wish to record our thanks to everyone involved, both with the 2018 Veritas Research Symposium and with the production of this special theme issue of Theofilos.

We trust that this Supplement edition of Theofilos will provide an introduction to and overview of key issues in the interdisciplinary field of Science, Natural Theology and Christian Apologetics, offering some fresh perspectives on these issues, whilst stimulating further reflections, a continued conversation, and future contributions on these themes.

\section{Peter S. Williams}

Southampton, December 2020

Guest Editor

1 See https://veritaskonferansen.no/. 